\title{
USO DA TERRA, VULNERABILIDADE E SUBSÍDIOS AO ORDENAMENTO TERRITORIAL EM MICROBACIA
}

\author{
land use, vulnerability and subsidy for planning in watershed \\ Josandra Araújo Barreto de Melo* \\ Eduardo Rodrigues Viana de Lima**
}

\begin{abstract}
Resumo
A Microbacia do Riacho do Tronco, Boa Vista, PB, está inserida no Semiárido brasileiro, onde as atividades desenvolvidas - agricultura, pecuária e mineração, sem práticas conservacionistas, vem provocando degradação ambiental, com tendência ao desencadeamento de processos de desertificação. A partir do exposto, o presente trabalho objetiva diagnosticar as principais formas de uso da terra, as vulnerabilidades da população e apresentar uma proposta de ordenamento para as atividades desenvolvidas no território da microbacia, subsidiando a gestão ambiental local. Como estratégia metodológica, foi realizada a integração de dados socioambientais, mediante interpretação de imagens de satélite e aplicação de questionários visando diagnosticar o grau de vulnerabilidade socioeconômica, tecnológica de infraestrutura para o enfrentamento das secas pela população da microbacia. A partir dessa integração de informações, foi elaborado um Plano de Ordenamento do Território da Microbacia que, se posto em prática, minimizará os riscos à desertificação no local.
\end{abstract}

Palavras-chave: Degradação Ambiental; Vulnerabilidades; Ordenamento do Território.

\section{Abstract}

The Watershed of Riacho do Tronco, Boa Vista, PB, is inserted in Brazilian semiarid, where the activities agriculture, livestock and mining, without conservation, is causing environmental degradation, tending to cause desertification. In this context, the present study aims to diagnose the forms of land use and vulnerabilities of population and propose the planning of activities developed within the watershed, subsidizing the local environmental management. As a methodological strategy, was made to integrate social and environmental data, by carrying of interpretation of satellite images and application of questionnaires to diagnose the degree of socioeconomic, technologic vulnerability and infrastructure to cope with droughts by the population. From this integration of information, was elaborated the planning of the territory of watershed that if implemented, minimize the risk of desertification in site.

Key words: Environmental Degradation, Vulnerability, Planning.

\section{Resumen}

La Cuenca del Riacho do Tronco, Boa Vista, PB, se inscribe en el Semiárido Brasileño, donde las actividades - la agricultura, la ganadería y la minería, sin técnicas de conservación, han causado la degradación del medio ambiente, con una tendencia a provocar la desertificación. En este contexto, se pretende diagnosticar las principales formas de uso de la tierra, la vulnerabilidad de la población y presentar una propuesta para la planificación de las actividades dentro de la cuenca,, contribuyendo a la gestión ambiental local. Como estrategia metodológica, se hizo para integrar datos sociales y ambientales, mediante la interpretación de images de satelite y la aplicación de cuestionarios para diagnosticar el nivel de vulnerabilidad socioeconómica, tecnología e infraestructura para hacer frente a las sequías por la población. A partir de esta integración de la información, fue un elaborado plan de la planificación de las cuencas que, de aplicarse, reducirá al mínimo el riesgo de desertificación en el local.

Palabras-claves:Degradación Ambiental; Vulnerabilidad; Ordenación del Territorio.

(*) Prof ${ }^{a}$. Dra . do Departamento de Geografia da Universidade Estadual da Paraíba - Rua Antônio Guedes de Andrade, 190, CEP: 58.100-970 - Campina Grande (PB) - Brasil, Tel: (+55 83) 33107117 - ajosandra@yahoo.com.br

(**) Bolsista Produtividade do CNPq, Prof. Dr. da Pós-Graduação em Geografia da Universidade Federal da Paraíba - Cidade Universitária, Castelo Branco III, CEP: 58.059-900 - Joao Pessoa (PB) - Brasil, Tel/Fax: (+55 83) 32167432 / 32167432 eduvianalima@gmail.com 


\section{INTRODUÇÃO}

A compreensão da complexidade da relação sociedade-natureza vem se ampliando a partir de meados do século XX, quando passou a haver uma maior percepção acerca dos problemas ambientais advindos do modelo de desenvolvimento vigente, impulsionando a ampliação dos desastres, cuja ocorrência se eleva devido a alta vulnerabilidade da população, quando a mesma não dispõe da infraestrutura para o enfrentamento das situações adversas.

A vulnerabilidade, categoria utilizada nos estudos de população e ambiente, passou por uma evolução conceitual, principalmente a partir da década de 1980. A evolução recente desses estudos ocorreu influenciada pelos avanços metodológicos e teóricos das ciências, como também por fatos ocorridos na sociedade atual que ampliaram e evidenciaram os perigos sociais, naturais e tecnológicos (HOGAN; MARANDOLA JR, 2007, p.74).

Segundo Marandola Jr. e Hogan (2005), no período anterior a década de 1980, tal categoria era analisada como idéia subjacente à noção de capacidade de resposta aos perigos naturais, incorporando a adaptação cultural como responsável pela criação de um nível de capacitação social para absorver os efeitos dos desastres ocasionados pelos perigos naturais. Em seguida, as pesquisas deixaram de dar atenção apenas aos perigos naturais e passaram a enfocar também os perigos sociais e tecnológicos, ou seja, a vulnerabilidade passou a aparecer em três contextos: social, tecnológico e ambiental passando-se, inclusive, a discutir sua gênese: seria a mesma um atributo dos condicionantes ambientais ou dos recursos socioeconômicos, que conferem maior ou menor capacidade de resposta aos perigos?

Segundo Marandola Jr. e Hogan (2005), a partir desses impasses, de acordo com a natureza da ciência a abordar a temática, tal categoria aparece como sendo o resultado de uma das três posturas: vulnerabilidade como condição preexistente, estabelecida a partir da espacialização da condição perigosa e da ocupação da população nessas áreas; vulnerabilidade como resposta controlada, sendo a mesma uma condição humana; e, vulnerabilidade do lugar, que incorpora a dimensão do risco biofísico, sua produção social e a capacidade de resposta dos indivíduos, conceito que se procura enfatizar neste trabalho.

A região semiárida do Brasil concentra o maior índice de pobreza do país e é acometida por frequentes secas. Estes aspectos, juntamente com as políticas implementadas na região, acarretam degradação ambiental e alto nível de vulnerabilidade da população, fazendo com que os anos de seca adquiram proporções de desastres, com número de vítimas semelhante a terremotos ou tsunamis (MELO, 2010, p. 35). O diferencial é que as consequências da seca se efetivam lentamente, embora com efeitos diários, matando animais ou até mesmo as pessoas.

A Microbacia do Riacho do Tronco encontra-se inserida em Boa Vista, município integrante do Semiárido paraibano, cuja média de precipitações foi de 416,3 mm/ano, entre os anos de 1923 e 1990 (GOVERNO DO ESTADO DA PARAÍBA/AESA, 2008), caracterizando-se como um dos mais castigados pelos efeitos da estiagem no Estado, com repercussões sobre a produção agrícola. Segundo informações disponibilizadas pelo IBGE (2006), não existe no município nenhuma modalidade de lavoura permanente, sendo o milho (Zea mays L.), feijão (Phaseolus Vulgaris L. ou Vigna unguiculata (L.) Walp), algodão (Gossypium hirsutum L.) e batata-doce (Ipomoea batatas (L.) Lam.) as únicas culturas agrícolas locais, dependente da disponibilidade de chuvas - escassas e mal distribuídas, deixando a população sujeita a extração de madeira para o fabrico do carvão, que chega a um montante de duas toneladas anuais e da lenha, que corresponde a um total de 2.900 $\mathrm{m} 3$ anuais.

Somado ao baixo desempenho socioeconômico está o fato de que, apesar de ainda restarem áreas conservadas na Microbacia, principalmente nas maiores propriedades, existem trechos que já se encontram degradados pelas causas já elencadas. Tal fato acarretará, se providências não forem tomadas para o ordenamento territorial, numa intensificação do processo de desertificação, definido pela Organização das Nações Unidas (UNEP, 1991) como sendo "a degradação das terras 
nas zonas áridas, semi-áridas e subúmidas secas resultante de vários fatores, incluindo as variações climáticas e as atividades humanas".

A elaboração do plano de ordenamento para a microbacia em análise procura romper com o paradigma tradicional, cujas políticas territoriais têm sido entendidas apenas no âmbito dos planos regionais de desenvolvimento, a partir da ação do Estado voltada para o enfoque regional específico, resultando comumente em projetos especiais que interessam a uma ou a outra região do país. Nesse entendimento, as políticas territoriais englobam toda e qualquer atividade estatal que implique, simultaneamente, uma dada porção do espaço nacional, uma estratégia de intervenção ao nível da estrutura territorial e, por fim, mecanismos concretos que sejam capazes de viabilizar essas políticas, levando-se em conta os anseios da população.

Neste caso, a microbacia hidrográfica representa uma região funcional, apta para a elaboração/execução de políticas territoriais, a partir da promulgação da Lei 9433/97 que institui a bacia hidrográfica como unidade de planejamento ambiental. Diante do exposto, esta abordagem objetiva diagnosticar as formas de uso das terras, o grau de vulnerabilidade da população e, a partir da integração dessas informações, subsidiar o ordenamento territorial, a partir da elaboração de um conjunto de programas, sub-programas e projetos passíveis de implementação no local, possibilitando a gestão territorial.

\section{MATERIAL E MÉTODO}

\section{Localização geográfica e aspectos relevantes da pesquisa}

Após a escolha da área de estudo, em função do conhecimento das características do meio físico, da hipótese de alta vulnerabilidade da população e da possibilidade de analisar as relações sociedade-natureza, foram empreendidos doze saídas de campo, com o georreferenciamento de 154 pontos de informações de interesse, que possibilitaram melhor distinguir os alvos nas imagens de satélite. Também foi estabelecido contato direto com a população, visando melhor compreender as práticas em curso na microbacia, suas causas e consequências. A partir desses esforços, a presente análise se desenvolveu através das etapas:

Delimitação e subdivisão da microbacia, geração das carta de declividade e solo

Este procedimento foi realizado a partir da sistematização das seguintes etapas:

. Delimitação da microbacia pelos divisores de água, identificados pela interpretação de fotografias aéreas cedidas pela Companhia de Desenvolvimento dos Recursos Minerais do Estado da Paraíba - CDRM, na escala de 1:70.000, datadas de 09 e 10 de dezembro de 1967; O produto final foi digitalizado e, posteriormente, importado pelo SPRING. Para a fotointerpretação, foi utilizado equipamento estereoscópico de espelho.

. Criação do Banco de Dados no SPRING 4.3, a partir das informações das fotografias aéreas, da carta topográfica do município de Boqueirão, em escala de 1:100.000, elaborada pela SUDENE (1972) e de imagens do satélite CBERS-2, sensor CCD, órbita 147, ponto 108, com resolução espacial de 20 metros, com data de 06 de abril de 2007.

. Importação para o SPRING dos dados de altimetria obtidos de imagens do SRTM, que possibilitaram a elaboração das curvas de nível, com eqüidistância de 5 metros, permitindo a geração do Modelo Numérico do Terreno - MNT e da grade triangular que originou o mapa de Declividade, com base nas classes propostas por De Biasi (1992).

. As curvas de nível, juntamente com a disposição da rede de drenagem possibilitou subdividir o território da microbacia em unidades menores, denominadas de sub-microbacias, conforme metodologia utilizada por Scapini (2006). 
. Geração do mapa de Solo, a partir da importação para o SPRING da Carta de Solo elaborada pelo Zoneamento Agropecuário da Paraíba (1978). O Sistema Brasileiro de Classificação de Solos (2006) permitiu a atualização das nomenclaturas das classes de solos.

\section{Diagnóstico de uso/ocupação das terras}

Ocorreu a partir de Processamento digital das imagens, pautado nos elementos texturais do relevo, drenagem e outros alvos, conforme metodologia proposta por Soares e Fiori (1976) para fotografias aéreas, adaptada por Veneziani e Anjos (1982) para imagens orbitais.

Tal metodologia de análise das imagens consiste numa seqüência de etapas sistemáticas que independem do conhecimento prévio da área, a partir da utilização dos processos fotointerpretativos. Entretanto, tal método foi enriquecido com o aporte de dados auxiliares, obtidos em campo. Os procedimentos adotados no processamento das imagens foram:

- Transformação das imagens: as imagens brutas foram processadas pelo módulo IMPIMA, integrante do SPRING, para o recorte da área de interesse e transformação do formato TIFF para o formato GRB.

- Georreferenciamento: realizado através da criação de seis pontos de controle marcados na carta topográfica, a partir de aspectos singulares da rede de drenagem e estradas. Utilizou-se a projeção do sistema de coordenadas UTM e datum SAD-69.

- Segmentação: foi realizada pelo Método de Crescimento de Regiões, com similaridade igual a cinco e área pixel igual a 20. Tal método consiste no agrupamento de dados no qual somente as regiões adjacentes, espacialmente, podem ser agrupadas.

- Classificação de padrões: foi utilizado o método Extração de Regiões, a partir das fases de treinamento, classificação e mapeamento. Neste procedimento, o algoritmo extrai as informações estatísticas de média e variável de cada região, considerando as bandas indicadas no contexto. Também se utilizou o classificador Bhattacharya, com limiar de aceitação de 99,9\%. Ao final, todas as regiões ficaram associadas a uma classe definida pelo algoritmo, relacionando-se os temas às classes definidas na criação do modelo de dados. A vetorização da imagem classificada foi realizada através da função Mapeamento.

- Medidas de classes: foi realizada a leitura das medidas de classes (vegetação densa, vegetação semi-densa, pecuária, agricultura, solo exposto, mineração, e reservatórios de água), possibilitando a elaboração dos percentuais e o diagnóstico do uso das terras;

- Editoração dos mapas temáticos: os mapas foram criados no módulo SCARTA, software complementar que acompanha o SPRING;

\section{Diagnóstico das vulnerabilidades da população local}

A metodologia utilizada para determinar as vulnerabilidades foi elaborada no Centro Interamericano de Desenvolvimento de Águas e Terras - CIDIAT, sediado na Venezuela. Foi adaptada para o contexto do Semiárido brasileiro por Barbosa (1997). Neste caso, o estudo consistiu num levantamento, através de questionários aplicados em todas as residências de cada sub-microbacia, a partir dos quais foi determinado o grau de vulnerabilidade social, econômica, tecnológica e de infra-estrutura à convivência com as secas. Convém mencionar que nas sub-microbacias 5 e 8 não existem residências. O Quadro 1 apresenta a distribuição do número de residências por sub-microbacia. 
Quadro 1 - Número de residências por sub-microbacia

\begin{tabular}{|c|c|c|c|c|c|c|c|c|}
\hline \multicolumn{1}{|c|}{ SUB-MICROBACIAS } \\
\hline Sub-microbacias & $\mathbf{1}$ & $\mathbf{2}$ & $\mathbf{3}$ & $\mathbf{4}$ & $\mathbf{5}$ & $\mathbf{6}$ & $\mathbf{7}$ & $\mathbf{8}$ \\
\hline Número total de residências & 41 & 10 & 02 & 16 & 00 & 04 & 08 & 00 \\
\hline
\end{tabular}

Os questionários tiveram variáveis que investigaram as características e atividades desenvolvidas nos núcleos familiares, com destaque para os seguintes fatores:

- Vulnerabilidade Social: variáveis: demográfica, habitação, consumo de alimentos, participação em organizações associativas e salubridade rural;

- Vulnerabilidade Econômica: variáveis: produção agropecuária, animais de trabalho e de produção, verticalização no aproveitamento de matérias-primas, comercialização, crédito e rendimento;

- Vulnerabilidade Tecnológica: variáveis: uso de tecnologias, propriedade das máquinas e equipamentos;

- Vulnerabilidade à Seca: variáveis: recursos hídricos, produção, manejo da Caatinga, exploração de espécies nativas, armazenamento, redução dos rebanhos, observação das previsões de chuvas, ocupação nas estiagens, educação, administração rural, histórico das secas, sugestões e migração.

No tratamento das informações contidas nos questionários foi identificada a moda de cada uma das variáveis que compõem cada fator analisado, que recebeu um peso específico. A soma dos pesos de cada um dos fatores possibilitou o cálculo do grau de vulnerabilidade, com valores que podem variar de zero a 100\%. Barbosa (1997) estipulou quatro classes para os valores de vulnerabilidades distribuídos entre zero e 100\%: 0 - 15\% baixa, 16 - 30\% moderada; 31 - 45\% alta e maior que $45 \%$ muito alta. Para o cálculo do grau de vulnerabilidade foi utilizada a equação seguinte:

$$
\begin{aligned}
& \mathrm{V}=\mathrm{ax}+\mathrm{b} \\
& \mathrm{ax}+\mathrm{b}=0 \\
& \mathrm{ax} \mathrm{x}^{\prime}+\mathrm{b}=100
\end{aligned}
$$

Sendo:

$\mathrm{x}=$ valor mínimo encontrado

x' = valor máximo encontrado

$\mathrm{V}=$ vulnerabilidade variando de zero (nula) até 100 (máxima)

$\mathrm{a}$ e $\mathrm{b}=$ constantes para cada fator

\section{Elaboração do plano de ordenamento territorial}

Para fins de sistematização desta etapa do trabalho, foi utilizada como referência a metodologia proposta por Orea (2007). A Figura 1 esquematiza as fases constituintes do plano de ordenamento territorial apresentado. 


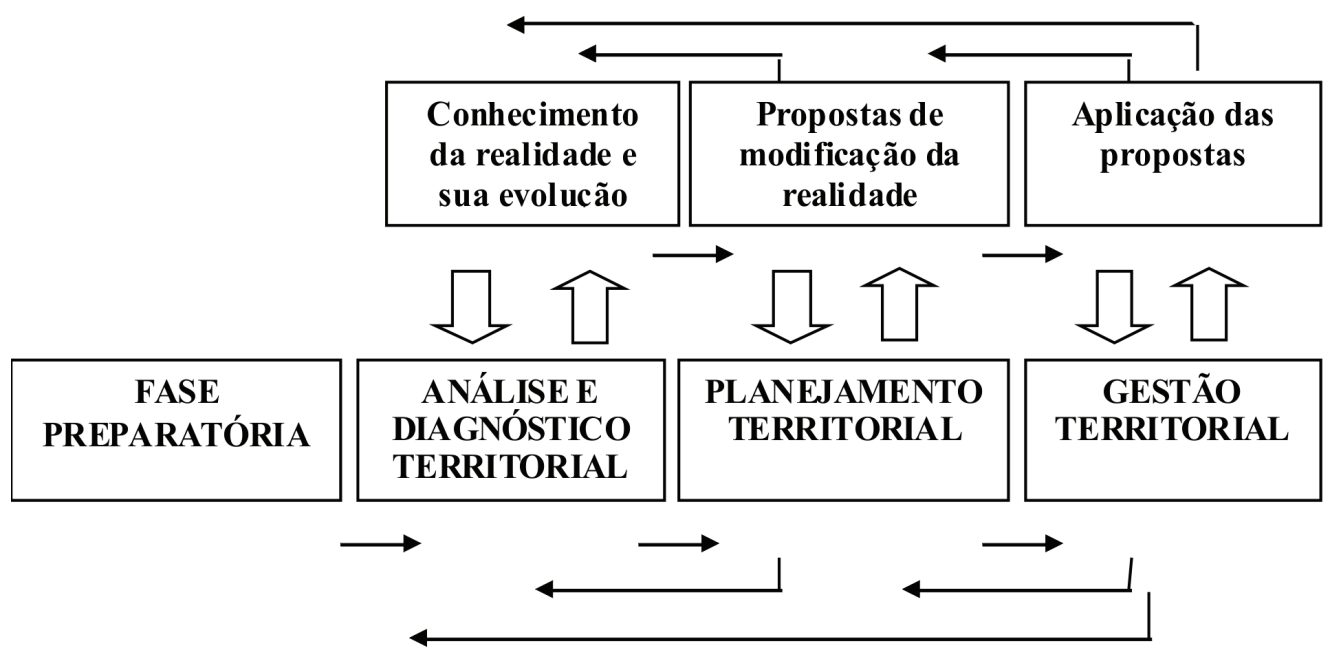

Figura 1 - Fases que constituem a elaboração de um Plano de Ordenamento Territorial. Fonte: Orea (2007, p. 137).

A estruturação apresentada distingue quatro fases descritas a seguir:

- Fase preparatória: trata-se do projeto que contém a representação cartográfica do espaço, a problemática, sua filosofia, a legislação aplicada, o conteúdo e o alcance.

- Fase de informação e diagnóstico: se refere a interpretação do sistema territorial à luz de sua evolução histórica e de sua tendência futura na ausência de intervenção, implicando em entender como é e como funciona o sistema, que problemas lhe afetam e de que potencialidades se dispõe. Através do esquema disposto na Figura 2, Orea (2007, p. 163) propõe a sintetização das informações necessárias a esta fase do plano:

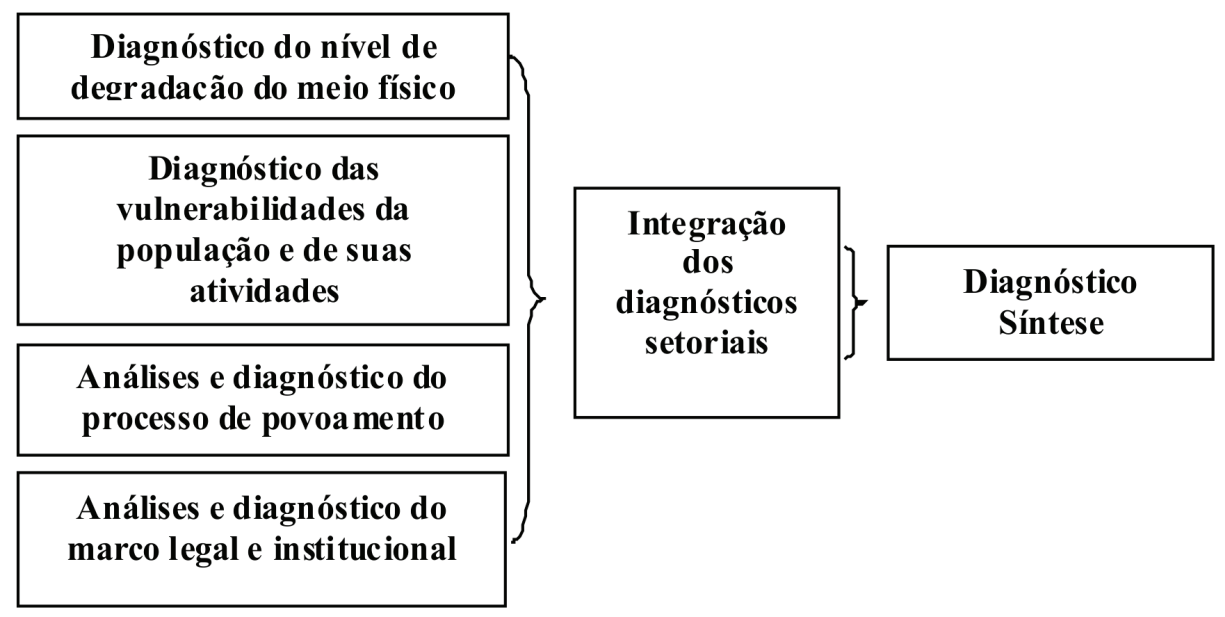

Figura 3: Elaboração do diagnóstico para subsidiar o Plano de Ordenamento Territorial de uma área. Fonte: Orea (2007, p. 161), adaptado.

- Fase de planejamento: a formalização desta fase se deu a partir das seguintes etapas:

- Identificação das potencialidades ambientais: consiste no inventário das atividades desenvolvidas nas sub-microbacias e na análise da compatibilidade ambiental das mesmas, classificando-as em vocacionais, compatíveis sem limitações, compatíveis com limitações, compatíveis com avaliação de impacto ambiental e incompatíveis. 
- Instrumentação das medidas: a operacionalização ocorreu a partir dos elementos: Zoneamento do território: possível a partir das categorias de ordenamento; Normatização associada ao zoneamento: normas reguladoras do uso do solo e de comportamento dos agentes socioeconômicos; Um programa de intervenção organizado em sub-programas, projetos ou outras ações.

- Identificação das categorias de ordenamento: realizada a partir dos critérios da abordagem sistêmica, que norteiam as sugestões das formas de uso do território, procurando garantir a preservação, conservação e exploração sustentada dos recursos naturais. São identificadas a partir do diagnóstico das classes de uso e do estado de conservação em que se encontram. No presente contexto, foram adotadas as seguintes categorias de ordenamento: Zonas de máxima proteção: foram definidas em conformidade com o Código Florestal Brasileiro (Lei 4.771/1965) e a Resolução CONAMA 303/2002; Zonas de uso restrito: Pelos princípios do Código Florestal do Estado da Paraíba (Lei 6002/1994), as florestas nativas e demais formas de vegetação natural existentes no Estado, reconhecidas de utilidade das serras que recobrem, são consideradas bens de interesse a todos os habitantes, exercendo-se os direitos de propriedade com limitações; Zonas de uso agrícola: são aptas para o desenvolvimento das atividades agrícolas; Zonas de uso pecuário: são as áreas para o desenvolvimento das atividades pecuárias; Zonas de recuperação ambiental: áreas com processos erosivos significativos.

- Normatização associada às categorias de ordenamento: esta elaboração também levou em consideração as políticas de uso de recursos naturais e de preservação e conservação ambiental vigentes na legislação brasileira e paraibana. Dessa forma, as alternativas elaboradas tiveram como princípio norteador a obediência aos seguintes instrumentos legais: O princípio da função social da propriedade - que define a estrutura do direito de propriedade, impondo limites ao seu exercício. Está presente na Constituição Federal de 1988; Lei nº 4.504/64 (Lei da Reforma Agrária) - no que tange aos artigos: $5^{\circ}$, que trata da dimensão da área dos módulos rurais; $16^{\circ}$, que estabelece a gradual extinção do latifúndio; Lei n ${ }^{\circ}$ 4.771/65 (Código Florestal) - foram consideradas importantes normatizações como a necessidade de delimitação das Áreas de Preservação Permanente e de Reserva Legal; Lei $n^{\circ}$ 6.938/81 (Política Nacional do Meio Ambiente) - foram considerados os objetivos (art. $2^{\circ}$ ) e conceitos (art. $3^{\circ}$ ); Lei $\mathrm{n}^{\circ}$ 8.171/91 (Política Agrícola) - foram considerados o art. $10^{\circ}$, que declara ser o solo patrimônio natural do país; art. $21^{\circ}$, que trata da desertificação, determinando que o Poder Público deve estabelecer cadastros de áreas sujeitas a desertificação; art. 19º , que estabelece que o Poder Público deverá fiscalizar o uso racional do solo, água, fauna e flora; Lei no. 9.433/97 (Política Nacional de Recursos Hídricos), que cria o Sistema Nacional de gerenciamento de Recursos Hídricos, cuja unidade territorial adotada é a bacia hidrográfica, no que tange ao art. $1^{\circ}$, que estabelece que a gestão deve ser descentralizada e participativa, modelo que pode ser adotado no Ordenamento Territorial; Decretos 24.414/2003, 24.416/2003, 24.417/2003 e 18.378/1996 que dispõem, respectivamente, sobre a exploração e reposição florestal obrigatórias, o uso alternativo do solo e estrutura organizacional básica do sistema integrado de planejamento e gerenciamento dos recursos hídricos no Estado da Paraíba e dá outras providencias; Leis Estaduais 6002/1994 e 6308/1996 que instituem, respectivamente, o Código Florestal do Estado da Paraíba e outras providências e a Política Estadual de Recursos Hídricos, suas diretrizes e outras providências.

- Programa de intervenção: apresentado de forma agrupada em blocos hierárquicos em termos de programas, sub-programas e projetos.

- Fase de Gestão: se trata de aplicar o Plano elaborado, dando segmento, realizando avaliações constantes. Esta fase não constitui objetivo deste trabalho, cabendo a população local, em conjunto com o poder público e as instituições em geral, colocá-lo em prática. 


\section{RESULTADOS E DISCUSSÃO}

\section{Subdivisão da área da microbacia, níveis de declividade e classes de solo}

A microbacia do Riacho do Tronco apresenta área de 10.556,52 ha. Para a realização deste estudo, a mesma foi subdividida em oito sub-microbacias. As respectivas unidades foram delimitadas respeitando-se a configuração geomorfológica, identificada a partir das curvas de nível, com eqüidistância de 5 metros. A Figura 3 apresenta a subdivisão da área.

As curvas de nível foram extraídas dos dados de altimetria de imagens do SRTM, sendo ajustadas ao contexto da microbacia mediante procedimento de interpolação. Embora se reconheça as limitações deste procedimento, principalmente nas áreas com maior diversidade nas formas de relevo, neste caso o trabalho de campo permitiu utilizar a técnica sem possibilidade de produzir erros, haja vista o único diferencial de relevo significativo ser o divisor sul da microbacia, estando as outras áreas em níveis que variam entre 450 e $500 \mathrm{~m}$.

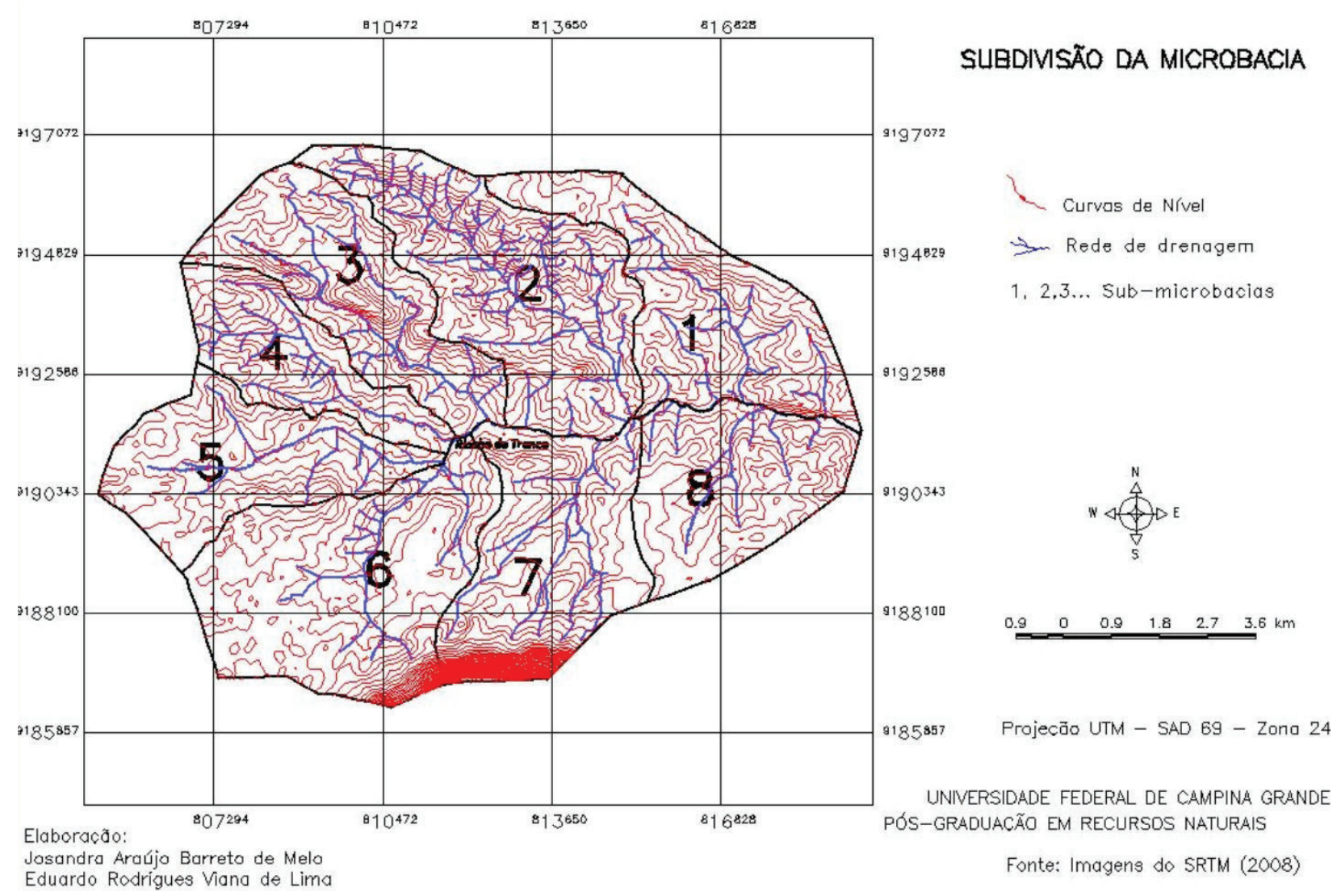

Figura 3 - Subdivisão da microbacia do Riacho do Tronco.

Com relação à declividade, a Figura 4 apresenta os intervalos das classes calculados, seguindo metodologia proposta por De Biasi (1992).

Verifica-se que a declividade é bastante suave, entretanto, nas partes mais altas da Serra do Monte supera 40\%, embora isso só corresponda a 0,13\% da área total. Quanto as classes de solo, a Figura 5 apresenta a nomenclatura das associações de solo encontradas no local.

Com ralação aos solos, podem ser enquadrados em quatro associações, que apresentam Caatinga hiperxerófila, fase pedregosa e/ou rochosa, relevo que varia de plano a suave ondulado, com exceção da área da Serra do Monte, local onde é classificado como forte ondulado e montanhoso. 


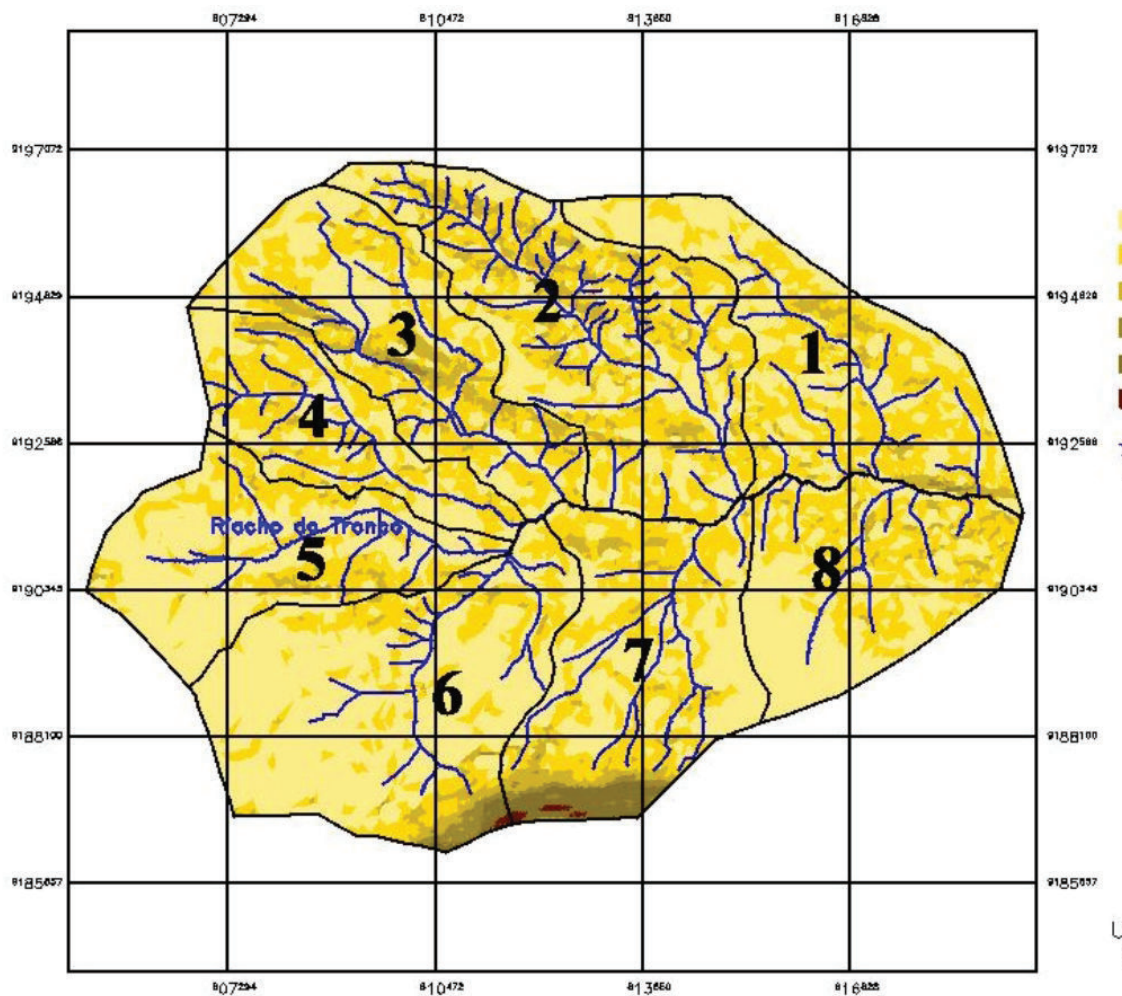

$0-3 \%$ - várzea

$3-6 \%$ - plano a suave ondulado

$6-12 \%$ - suave ond. a ondulado

$12-20 \%$ - ondulado a forte ond.

$20-40 \%$ - forte ond. a mantonhoso

- > 40\%- montanhoso

$\rightarrow$ Rede de drenagem

$1,2,3 \ldots$ Sub-microbacias
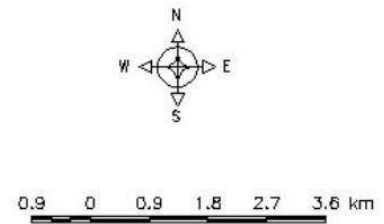

Projeç̃o UTM - SAD 69 - Zona 24

UNIVERSIDADE FEDERAL DE CAMPINA GRANDE PÓS-GRADUACÃO EM RECURSOS NATURAIS

Elaboração:

Josandra Araúio Barreto de Melo

Figura 4 - Classes de declividade da microbacia.

Complementarmente, acrescenta-se que as análises dos parâmetros densidade absoluta e relativa e porosidade total do solo, realizadas por Melo (2010) diagnosticaram que os solos do local apresentam alta propensão à compactação e, consequentemente à desertificação.

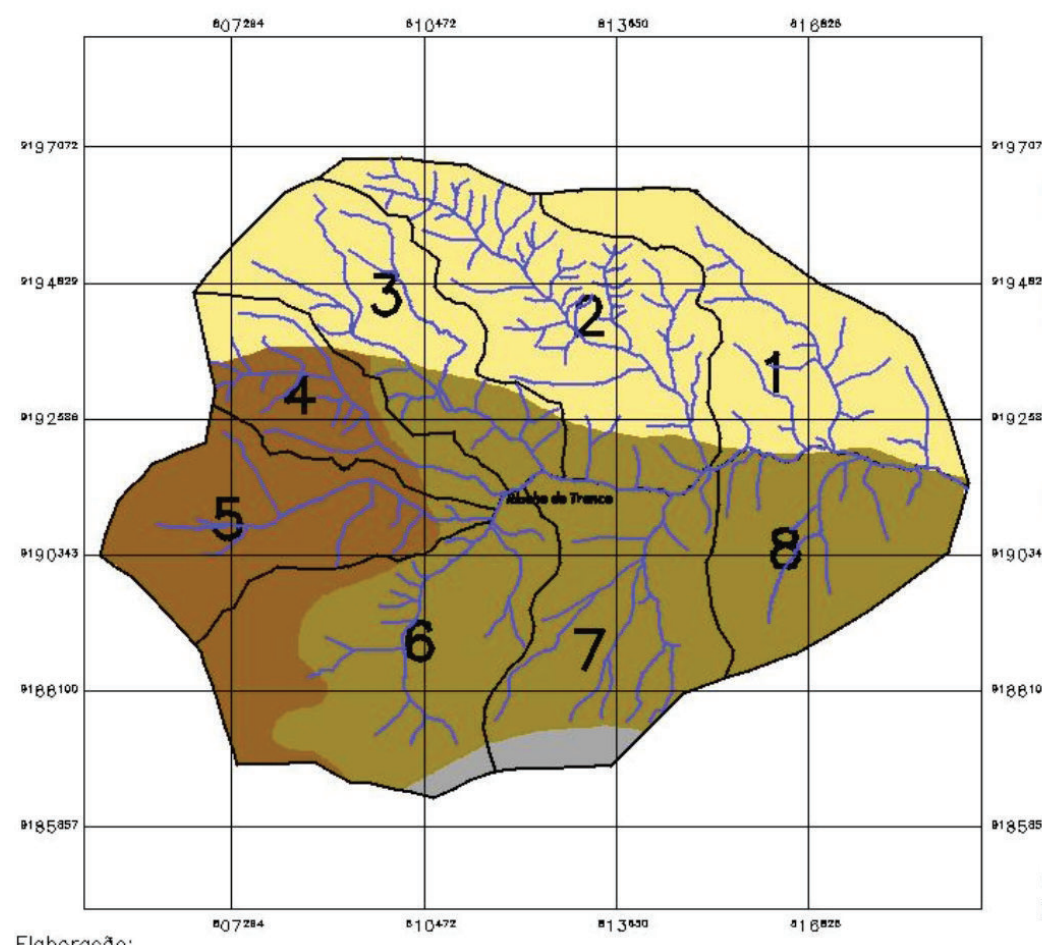

CLASSES DE SOLOS

Josandra Araúja Barreto de Melo

Eduardo Rodrigues Viana de Lima

- Assoc. entre LUVISSOLOS CRÔMICOS Orticos Vertissólicos, NEOSSOLOS UTó́licas Eutróficos Típicos e PLANOSSOLOS NÁTRICOS Sálicos Típicos Assoc, entre LUVISSOLOS CRÔMICOS HÁPUICOS Orticos T'́picos e NEOSSOLOS LITÓLICOS Eutróficos Típicos

- Assoc. entre NEOSSOLOS LITбLICOS Eutróficos Típicos e AFLORAMENTOS DE ROCHAS

$S$ Assoc. entre PLANOSSOLOS NÁTRICO ITÓLICOS Sólicos Típicos e NEOSSOLOS

$1,2,3 \ldots$ Sub-microbacias

$\rightarrow$ Rede de drenagem

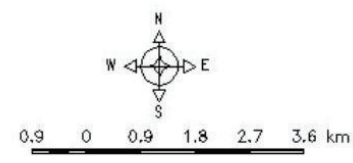

Projeção UTM - SAD 69 - Zona 24

UNIVERSIDADE FEDERAL DE CAMPINA GRANDE PÓS-GRADUAACÃO EM RECURSOS NATURAIS

Fonte: Zoneamenta Agropecuário do Estado da Pararba, (1978) e Sistemo Brgsileiro de

Figura 5 - Classes de solo presentes na microbacia. 


\section{Diagnóstico de uso/ocupação das terras}

Através de técnicas de geoprocessamento e trabalho de campo, efetuou-se a classificação da imagem, identificando-se as classes constantes na Figura 6.

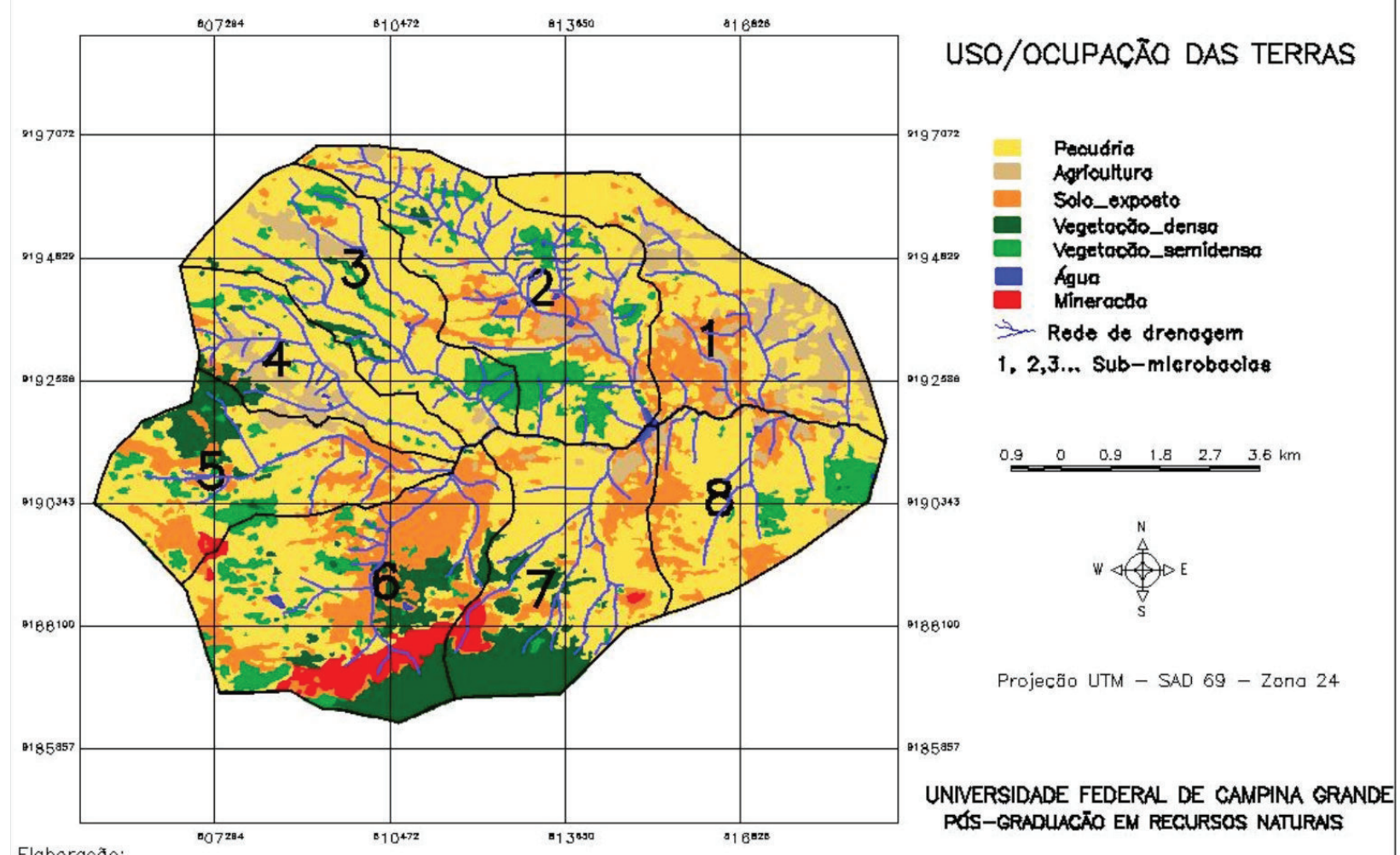

Jasandra Ará́ia Barreta de Melo

Figura 6 - Mapa de Uso/ocupação das terras da Microbacia.

A Tabela 1 quantifica as classes de uso/ocupação das terras por sub-microbacia e na íntegra. A associação da referida tabela à Figura 7 permite verificar que todas as unidades apresentam baixo percentual de vegetação densa ou Caatinga arbustivo-arbórea fechada, embora este percentual seja mais expressivo nas sub-microbacias cinco, seis e sete, sobretudo na área da Serra do Monte onde, segundo estudo feito por Oliveira et al. (2009) predominam em maior densidade as espécies C. pyramidalis, A. pyrifolium, C.sonderianus e B. cheilanth. Quanto à classe vegetação semi-densa ou Caatinga arbustiva aberta, nas sub-microbacias um e sete os percentuais são mais baixos que os demais e, como a primeira é a mais habitada e a sete, ocupada apenas com pastagens, explica-se os baixos quantitativos identificados.

Quanto a pecuária, os percentuais são muito representativos em todas as sub-microbacias, podendo a atividade ser apontada como a principal forma de uso das terras no local. Importante ressaltar que, segundo o Projeto de Avaliação Mundial da Degradação dos Solos, do PNUD, o superpastejo é o principal fator da degradação dos solos no mundo, com um percentual de 34,5\% na participação das pastagens nas áreas mundiais degradadas.

As áreas agrícolas são pouco expressivas, em decorrência das limitações hídricas. Os plantios são de milho (Zea mays L.) e feijão (Phaseolos vulgaris L.), que se desenvolvem no período de chuvas, e de palma (Opuntia ficus-indica Mill), que é utilizada como fonte de alimentação animal, tendo em vista seu potencial protéico e de adaptação às condições locais. 
Tabela 1 - Classes de uso/ocupação das terras na microbacia do Riacho do Tronco.

\begin{tabular}{|c|c|c|c|c|c|c|c|c|}
\hline $\begin{array}{l}\text { SUB- } \\
\text {-MICRO } \\
\text { BACIA }\end{array}$ & $\begin{array}{l}\text { ÁREA } \\
\text { (HA) }\end{array}$ & $\begin{array}{c}\text { VEGETAÇÃO } \\
\text { DENSA } \\
\text { (HA) }\end{array}$ & $\begin{array}{l}\text { VEGETAÇÃO } \\
\text { SEMI-DENSA } \\
\text { (HA) }\end{array}$ & $\begin{array}{c}\text { PECUÁRIA } \\
\text { (HA) }\end{array}$ & $\begin{array}{c}\text { ÁREAS } \\
\text { AGRÍCOLAS } \\
\text { (HA) }\end{array}$ & $\begin{array}{l}\text { ESPELHO } \\
\text { DE ÁGUA } \\
\text { (HA) }\end{array}$ & $\begin{array}{c}\text { MINERAÇÃO } \\
\text { (HA) }\end{array}$ & $\begin{array}{c}\text { SOLO } \\
\text { EXPOSTO } \\
\text { (HA) }\end{array}$ \\
\hline \multirow{2}{*}{1} & \multirow{2}{*}{$1.353,24$} & 1,24 & 3,04 & 697,36 & 357,68 & 2,72 & 0,00 & 291,20 \\
\hline & & $0,09 \%$ & $0,22 \%$ & $51,53 \%$ & $26,44 \%$ & $0,20 \%$ & $0 \%$ & $21,52 \%$ \\
\hline \multirow{2}{*}{2} & \multirow{2}{*}{$1.744,76$} & 9,12 & 266,52 & 1139,00 & 94,56 & 8,28 & 0,00 & 227,28 \\
\hline & & $0,52 \%$ & $15,27 \%$ & $65,28 \%$ & $5,43 \%$ & $0,47 \%$ & $0 \%$ & $13,03 \%$ \\
\hline \multirow{2}{*}{3} & \multirow{2}{*}{$1.229,16$} & 25,88 & 134,80 & 963,72 & 68,92 & 1,40 & 0,00 & 34,44 \\
\hline & & $2,10 \%$ & $10,97 \%$ & $78,40 \%$ & $5,62 \%$ & $1,11 \%$ & $0 \%$ & $2,80 \%$ \\
\hline \multirow{2}{*}{4} & \multirow{2}{*}{770,48} & 44,12 & 31,36 & 526,12 & 139,96 & 2,56 & 0,00 & 26,36 \\
\hline & & $5,73 \%$ & $4,07 \%$ & $68,28 \%$ & $18,17 \%$ & $0,33 \%$ & $0 \%$ & $3,42 \%$ \\
\hline \multirow{2}{*}{5} & \multirow{2}{*}{$1.150,52$} & 146,44 & 106,80 & 609,04 & 30,72 & 0,00 & 10,12 & 247,40 \\
\hline & & $12,73 \%$ & $9,28 \%$ & $52,93 \%$ & $2,68 \%$ & $0 \%$ & $0,88 \%$ & $21,50 \%$ \\
\hline \multirow{2}{*}{6} & \multirow{2}{*}{$1.854,52$} & 316,40 & 192,80 & 582,20 & 1,04 & 5,12 & 163,36 & 593,60 \\
\hline & & $17,06 \%$ & $10,39 \%$ & $31,39 \%$ & $0,06 \%$ & $0,28 \%$ & $8,81 \%$ & $32,01 \%$ \\
\hline \multirow{2}{*}{7} & \multirow{2}{*}{$1.371,92$} & 324,96 & 13,28 & 730,60 & 31,76 & 5,04 & 43,40 & 222,88 \\
\hline & & $23,69 \%$ & $0,98 \%$ & $53,25 \%$ & $2,31 \%$ & $0,37 \%$ & $3,16 \%$ & $16,24 \%$ \\
\hline \multirow{2}{*}{8} & \multirow{2}{*}{$1.081,92$} & 0,96 & 109,88 & 704,28 & 40,76 & 2,32 & 0,00 & 223,72 \\
\hline & & $0,09 \%$ & $10,16 \%$ & $65,09 \%$ & $3,77 \%$ & $0,21 \%$ & $0 \%$ & $20,68 \%$ \\
\hline \multirow{2}{*}{$\begin{array}{l}\text { Área } \\
\text { Total }\end{array}$} & \multirow{2}{*}{$10.556,52$} & 869,12 & 858,48 & 5.952 .32 & 765,4 & 27,44 & 216,88 & 1866,88 \\
\hline & & $8,23 \%$ & $8,13 \%$ & $56,39 \%$ & $7,25 \%$ & $0,26 \%$ & $2,05 \%$ & $17,68 \%$ \\
\hline
\end{tabular}

Quanto aos percentuais de solo exposto, não são decorrentes do uso das terras com agricultura, mas com pastagem (sub-microbacias um e oito) e mineração (sub-microbacias cinco e seis). A mineração não deixa solo exposto apenas nas áreas de exploração, mas nas áreas de prospecção e de deposição dos resíduos, conhecidos como rejeitos que, no caso presente, não são reaproveitados. As Figuras 7 A e B apresentam aspectos da situação mencionada.

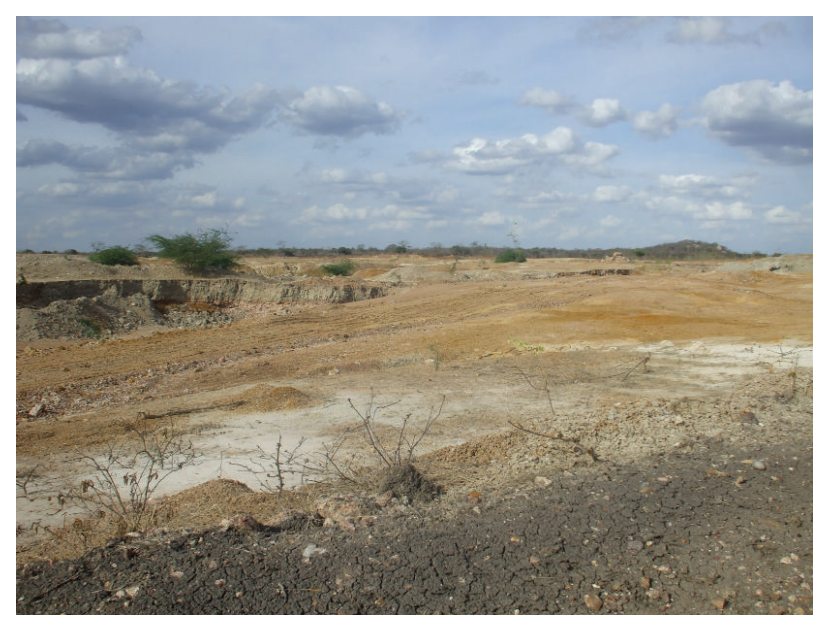

Figura 7A - Solo exposto nas imediações das minas.

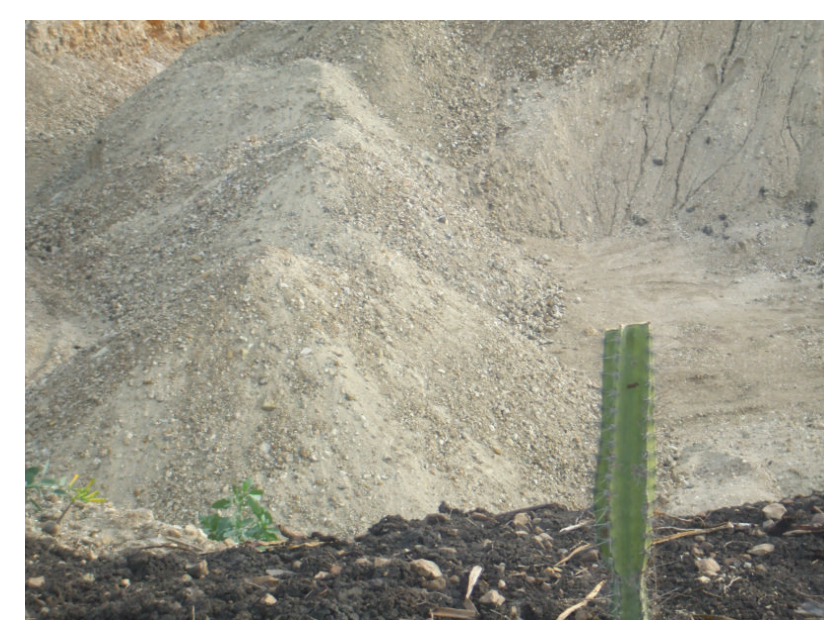

Figura 7B - Área de disposição de material estéril. Fonte: Trabalho de campo, realizado em 18 de janeiro de 2009.

As figuras são apenas a representação pontual de um impacto que atinge dezenas de $\mathrm{km}^{2}$. Quanto ao material estéril, ou seja, todo material descartado durante a lavra do minério (BALIEIRO, 2008, p. 105), a partir da fiscalização dos órgãos ambientais para o cumprimento do Decreto estadual 24.417/2003, vem sendo recobertos por uma camada de solo, reflorestada com espécies 
nativas - cactos e macambira (Bromelia laciniosa Mart ex Schultez f.), entretanto o êxito é pequeno, tendo em vista se tratar apenas de uma tentativa de remediação para cumprir exigências legais. As Figuras 8 A e B representam essas medidas.

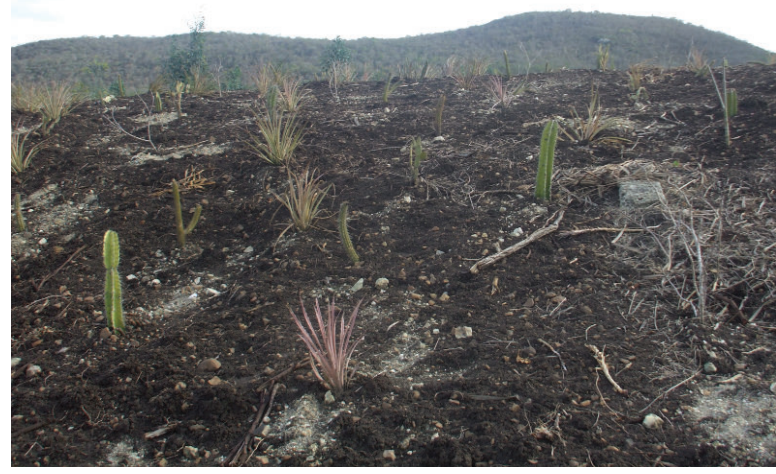

Figura 8A - Reflorestamento com espécies nativas.

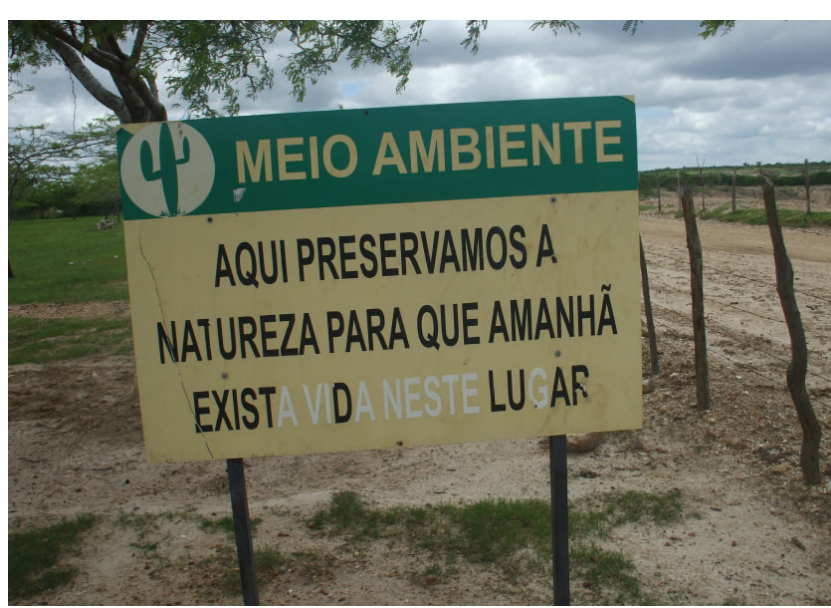

Figura 8B - Discurso formal das empresas mineradoras. Fonte: Trabalho de campo, realizado em 18 de janeiro de 2009.

Afora o material estéril e o rejeito, ainda são deixados abertos os taludes, que possuem diferentes conformações e dimensões, que impedem o desenvolvimento de qualquer atividade, além de constituírem impacto irreversível ao ambiente, conforme Figuras 9 A e B.
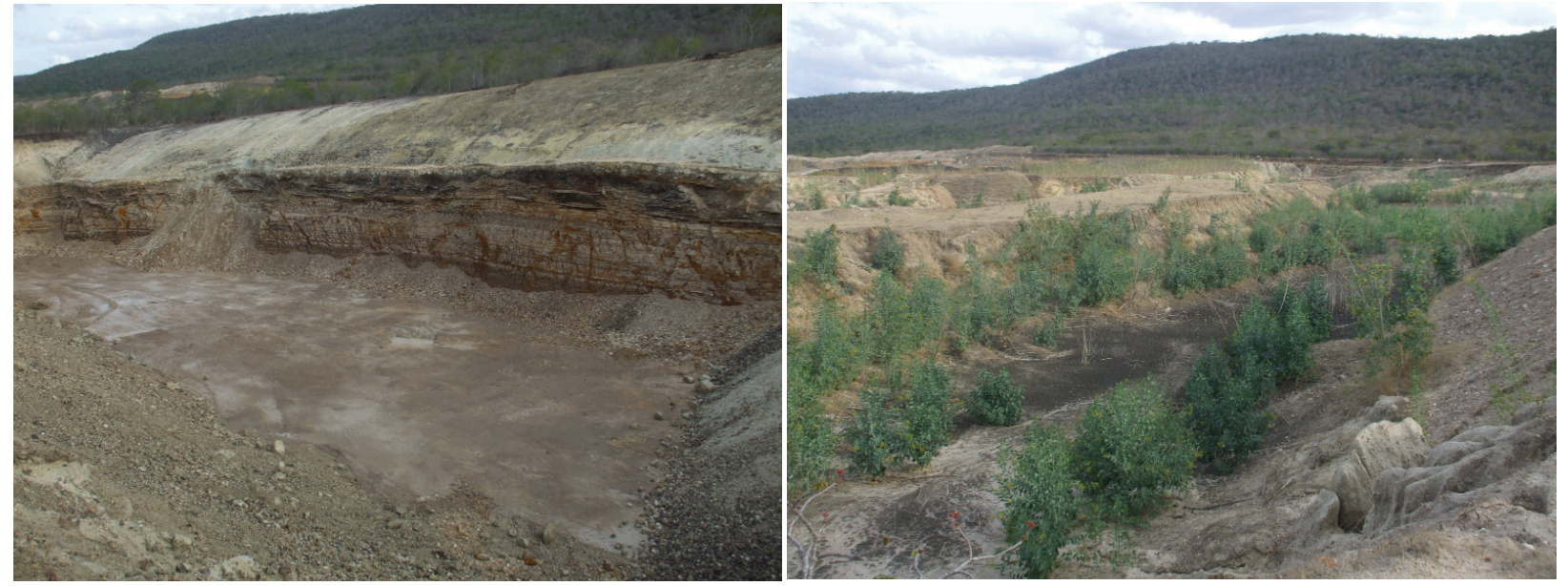

Figura 9A - Talude aberto em mina ativa. Figura 9B - Talude aberto em mina abandonada. Fonte: Trabalho de campo, realizado em 18 de janeiro de 2009.

Essas áreas deveriam ser recobertas, pois conforme a legislação ambiental, atualmente, o Plano de Recuperação de Áreas Degradadas (PRAD), a ser apresentado simultaneamente ao EIA e ao RIMA deve conter o plano de fechamento das minas (BALIEIRO, 2008, p. 92), tendo em vista que o uso futuro da área determina o grau de intervenção antrópica. Nas condições encontradas no local, o nível de antropismo é extremo, pois a mina não tem nenhuma possibilidade de recuperação, mesmo em longo prazo.

Somado a toda essa problemática, nesse local não há respeito às Áreas de Proteção Permanentes, pois a lavra evolui livremente sobre as áreas de nascentes e matas ciliares. A coibição para esse tipo de atitude só ocorreria com a demarcação oficial das APPs que vetaria no nascedouro os licenciamentos ambientais indevidos e a superação da deficiência estrutural do Estado, viabilizando a efetiva fiscalização das áreas ocupadas indevidamente.

Outra forma de degradação encontrada em toda a microbacia refere-se a presença intensiva da algaroba [Prosopis juliflora (Sw) DC] em substituição as matas ciliares e a vegetação nativa. Em 
todo o percurso realizado ao longo do leito do Riacho do Tronco e de seus afluentes, verificou-se a forte antropização e a incidência da mencionada espécie, fato que trás preocupações pelo forte potencial de competição oferecido por ela, o que reduz a diversidade vegetal da Caatinga, bem como o potencial de regeneração das outras espécies em seu entorno (PEGADO et al., 2006).

Uma das características típicas do Semiárido também foi observada na microbacia em análisetrata-se da pequena quantidade de reservatórios de água. O reservatório de maior representatividade na microbacia como um todo é o açude do Juá, que é o único a resistir ao período da estiagem, se a mesma não ultrapassar dois anos consecutivos. Outros dois açudes de maior capacidade de armazenamento de água (açudes São Pedro e Malhada) foram carreados pelas chuvas ocorridas nos anos de 2000 e 2004, cujas médias pluviométricas superaram $906 \mathrm{~mm}$ e $673 \mathrm{~mm}$, respectivamente, fenômenos atípicos no local.

Por fim, foi diagnosticado que na microbacia já existem sérios problemas erosivos, cuja gênese está associada à ausência de adoção de técnicas de conservação de solos.

\section{Vulnerabilidades da população local}

Assim como para o diagnóstico de uso/ocupação das terras, para a determinação das vulnerabilidades, a área da microbacia foi subdividida em oito sub-microbacias, embora nas unidades cinco e oito não existam residências, visando correlacionar as informações com as anteriores e subsidiar a elaboração do plano de ordenamento.

A Tabela 2 apresenta os níveis de vulnerabilidade social, econômica, tecnológica e de infra-estrutura para o enfrentamento às secas diagnosticada em cada uma das sub-microbacias da área em análise.

Tabela 2 - Nível de vulnerabilidades social, econômica, tecnológica e infra-estrutura às secas.

\begin{tabular}{l|c|c|c|c|c|c|c}
\hline \multirow{2}{*}{ VULNERABILIDADE } & \multicolumn{7}{|c|}{ SUB-MICROBACIAS (\%) } \\
\cline { 2 - 8 } & 1 & 2 & 3 & 4 & 6 & 7 & Geral \\
\hline Social & 36,05 & 37,98 & 37,49 & 39,42 & 39,42 & 40,86 & 38,54 \\
\hline Econômica & 83,33 & 76,19 & 78,57 & 80,95 & 69,05 & 66,67 & 75,79 \\
\hline Tecnológica & 81,48 & 81,48 & 92,59 & 81,48 & 85,19 & 81,48 & 83,95 \\
\hline Convivência com as secas & 63,93 & 62,29 & 68,85 & 62,29 & 62,29 & 60,65 & 63,38 \\
\hline
\end{tabular}

De acordo com a tabela, verifica-se que não há grande diferença entre os valores diagnosticados em cada sub-microbacia. Quanto à vulnerabilidade social, em todas as sub-microbacias, pode ser considerado um valor alto (entre 31 e $45 \%$ ). As demais vulnerabilidades, em todas as sub-microbacias, podem ser classificadas de valor muito alto (maior que $45 \%$ ), sendo mais comprometidos os aspectos econômicos e tecnológicos.

Os resultados diagnosticados na área de análise corroboram os encontrados por Sousa (2007), quando analisou as mesmas modalidades de vulnerabilidades nos municípios de Boa Vista, Cabaceiras, São João do Cariri, PB, São Domingos do Cariri e Itaporanga e com os encontrados por Alencar (2004), em Amparo e Ouro Velho, também na Paraíba.

No cálculo da vulnerabilidade social, as principais variáveis que comprometeram o índice foram a baixa escolaridade; a pequena área das propriedades, que não permite maiores possibilidades de usufruto/rendimento advindo da terra; a ausência de participação dos proprietários em associações comunitárias; o pequeno percentual de pessoas economicamente ativas por família; a utilização da lenha e carvão em substituição ou conjuntamente com o gás liquefeito; a eliminação ao ar livre dos dejetos e resíduos sólidos produzidos nas residências.

Contribuíram para amenizar o índice o maior acesso aos aparelhos eletrodomésticos (televisão, DVD e refrigerador); os alimentos consumidos, que incluem carne, leite e derivados do milho; o padrão das residências, construídas em alvenaria, com piso de cimento ou cerâmica e com boas condições de ventilação. De acordo com o estudo, essas melhorias podem ser atribuídas às políticas do governo federal para a população de baixa renda. Diferentemente da modalidade anterior, 
a vulnerabilidade econômica apresentou grau muito alto em todas as sub-microbacias, superando $45 \%$ (parâmetro de referência), variando de $66,67 \%$ na sub-microbacia sete até $85,19 \%$ na sub-microbacia seis. Os maiores agravantes foram as formas de venda da produção agropecuária que, quando existem, são feitas aos atravessadores; o rendimento anual proveniente da terra inferior a quinze salários mínimos, em quase 100\% das propriedades; a utilização das aposentadorias de parentes ou bolsas do governo federal como principais fontes de renda extra, quando existem; o fato de quase $100 \%$ dos proprietários não dispor de acesso às fontes de crédito bancário e a pequena quantidade de animais de trabalho por propriedade.

Quanto à vulnerabilidade tecnológica, os índices também foram muito altos, todos superando $80 \%$ e, no caso da sub-microbacia três, superando $90 \%$. As variáveis que ampliaram o índice foram o uso de técnicas arcaicas nas atividades produtivas, não conseguindo oferecer competitividade aos usuários; também exerceram papel significativo as formas como se dá o uso das terras com atividades que não levam em consideração as particularidades ambientais locais, que conferem uma maior ou menor potencialidade de uso, a exemplo do plantio em áreas de declives, da ausência de utilização de práticas conservacionistas do solo, do uso do solo inapto para determinadas atividades, provocando conflitos de uso. Estes resultados corroboram os encontrados por Pereira e Barbosa (2009), numa microbacia em São João do Rio do Peixe, PB.

Por fim, a vulnerabilidade às secas que, em todas as sub-microbacias, superou $60 \%$, devido a incapacidade da população de criar mecanismos para a convivência com o fenômeno das secas. Tal infraestrutura pode ser traduzida na presença de fontes de água de consumo nas propriedades; na forma de abastecimento domiciliar de água, a partir da utilização de reservatórios e utensílios com melhores condições de higiene e conforto; na captação de água de chuva pelos telhados das residências, através de cisternas; na prática de armazenamento de alimentos, tanto para a população quanto para os animais, dentre outras variáveis.

A partir desse quadro, verifica-se que o estudo das vulnerabilidades associado ao diagnóstico de uso/ocupação das terras é essencial para que se viabilize a elaboração e implementação de políticas públicas de convivência com as características do Semiárido e, conseqüentemente, que se alcancem os princípios do desenvolvimento sustentável.

\section{Proposta de ordenamento do território da microbacia do Riacho do Tronco}

Pelo diagnóstico, verifica-se que os problemas socioambientais da Microbacia derivam de dois tipos de ações que se ramificam em várias relações de causa-efeito.

- Problemas derivados do uso/ocupação indiscriminada das terras

Não existe planejamento de uso das terras, que são ocupadas com atividades agropecuárias, sem acompanhamento técnico ou adoção de técnicas conservacionistas e com extração da argila Bentonita em algumas sub-microbacias. Nesta atividade, geralmente não se inclui a variável ambiental nos planos de extração e não há recuperação das áreas degradadas, descumprindo a determinação do Decreto estadual no 24.417/2003.

As práticas agrícolas são realizadas com culturas de subsistência, com instrumentos ancestrais, conforme o diagnóstico de vulnerabilidades tecnológicas. Geralmente, se desenvolvem nas áreas mais úmidas representadas pelos poucos terrenos aluvionais existentes. Já a pecuária, é desenvolvida extensivamente, sem técnicas conservacionistas.

\section{- Problemas socioeconômicos limitadores}

De acordo com os diagnósticos, foi possível verificar a alta vulnerabilidade da população, em todas as modalidades. A maioria das famílias possui baixo nível de escolaridade e renda inferior a um salário mínimo, derivada da terra e de atividades dependentes das chuvas, numa região de clima Semiárido, onde não existem políticas públicas eficazes de convivência com o fenômeno da seca 
e onde as ações que foram implementadas pelo Estado para sanar os problemas, ampliaram ainda mais as desigualdades sociais.

O nível de vulnerabilidades vivenciado pela população lhe distancia das transformações ocorridas no espaço mundial, decorrentes da emergência de uma nova ordem e da globalização. Na verdade, a maioria da população aparenta viver em outro tempo social.

Pelo exposto, fica clara a problemática socioambiental local. Para fins de operacionalização da proposta de ordenamento, foi utilizado o conceito de aptidão natural, que expressa a relação entre o meio e as atividades humanas em termos de vocacionalidade, compatibilidade e incompatibilidade. Dado que o meio não é homogêneo, para determinar sua aptidão se fez uso da subdivisão da microbacia em unidades menores, as sub-microbacias, que são as unidades do território identificadas a partir das análises setoriais realizadas. $\mathrm{O}$ interesse em tais unidades se deu porque as potencialidades não dependem dos recursos ambientais isoladamente, por mais importantes que sejam, mas a partir de sua interação sistêmica.

Sobre as sub-microbacias foram contabilizados os méritos ou valores de conservação do território, as degradações que lhe afetam, as ameaças derivadas das atividades humanas e a vulnerabilidade da população, sendo possível direcionar o uso das terras em cada sub-microbacia, conforme representação mediante a Figura 11.

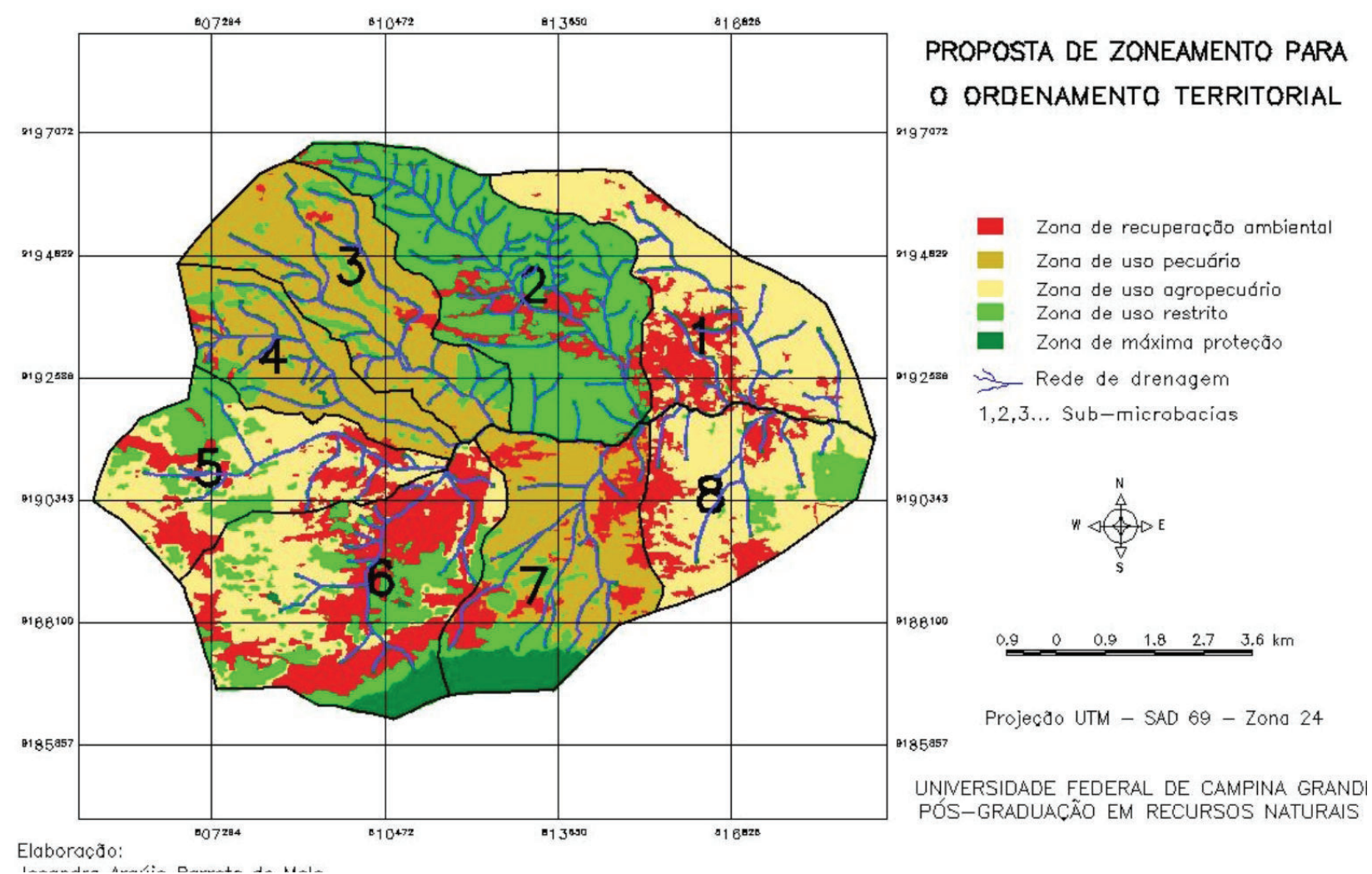

Figura 11: Proposta de Ordenamento Territorial para a Microbacia do Riacho do Tronco.

A partir da Figura 11, foi elaborado o Quadro 2 que apresenta a Matriz de potencialidades ambientais para o desenvolvimento das atividades nas sub-microbacias. 
Quadro 2- Matriz de potencialidades ambientais na Microbacia.

\begin{tabular}{|c|c|c|c|c|c|c|c|c|c|}
\hline & \multicolumn{9}{|c|}{ SUB-MICROBACIAS } \\
\hline ATIVIDADES A CONSIDERAR & & 1 & 2 & 3 & 4 & 5 & 6 & 7 & 8 \\
\hline \multirow{5}{*}{ PRODUTIVAS } & CS & $\mathrm{V}$ & I & 1 & 1 & $\mathrm{~V}$ & $\mathrm{~V}$ & 1 & $\mathrm{~V}$ \\
\hline & $\mathrm{Cl}$ & $\mathrm{V}$ & I & 1 & 1 & $\mathrm{~V}$ & $\mathrm{~V}$ & 1 & $\mathrm{~V}$ \\
\hline & PA & $\mathrm{V}$ & I & $\mathrm{v}$ & $\mathrm{V}$ & $\mathrm{v}$ & $\mathrm{V}$ & $\mathrm{V}$ & $\mathrm{V}$ \\
\hline & FP & $\mathrm{CL}$ & 1 & 1 & 1 & $\mathrm{CL}$ & $\mathrm{CL}$ & 1 & $\mathrm{CL}$ \\
\hline & MI & NA & NA & NA & NA & $\mathrm{Cl}$ & $\mathrm{Cl}$ & $\mathrm{Cl}$ & NA \\
\hline \multirow{3}{*}{$\begin{array}{l}\text { CONSERVAÇÃO E REGENERAÇÃO } \\
\text { DA NATUREZA }\end{array}$} & RSFC & c & c & c & c & $\mathrm{C}$ & C & $\mathrm{C}$ & C \\
\hline & PT & NA & $\mathrm{V}$ & NA & NA & NA & NA & NA & NA \\
\hline & RA & c & C & C & C & C & C & $\mathrm{C}$ & C \\
\hline \multirow{2}{*}{ RECREATIVAS } & GT & $\mathrm{CL}$ & $\mathrm{CL}$ & $\mathrm{CL}$ & $\mathrm{CL}$ & $\mathrm{CL}$ & $\mathrm{CL}$ & $\mathrm{CL}$ & $\mathrm{CL}$ \\
\hline & PC & NA & NA & NA & NA & NA & NA & $\mathrm{CL}$ & NA \\
\hline
\end{tabular}

V: vocacional; C: compatível sem limitações; CL: compatível com limitações; CI: compatível com avaliação de impacto ambiental; I: incompatível; NA: não aplicável.

CS - Culturas de Sequeiro; CI - Culturas Irrigadas; PA - Pastagem; FP - Florestas plantadas; MI - Mineração; RSFC - Reflorestamento sem fins comerciais; PT - Preservação total; RA - Recuperação ambiental; GT - Geoturismo; PC - Pesca.

Trata-se de procediemnto a possibilitar indicação de programas, com seus respectivos subprogramas e projetos de intervenção voltados ao ordenamento territorial da microbacia:

. Educação contextualizada, conscientização e formação ambiental

1. Educação regular para crianças e adultos não alfabetizados: Alfabetização e inserção da vivência dos alunos no cotidiano escolar.

2. Educação ambiental às crianças, jovens e adultos: Inclusão de temas ambientais e do contexto local nas disciplinas escolares; Realização de aulas de campo com os alunos, enfatizando as potencialidades autóctones e a necessidade de conservação.

3. Sensibilização ambiental dirigida às autoridades locais, aos agentes socioeconômicos e à população em geral: Edição de material didático sobre os recursos naturais da microbacia, enfatizando o princípio da responsabilidade compartilhada.

4. Formação de quadros para a gestão ambiental: Convênio com as universidades para a formação de quadros em matéria ambiental, voltado para os campos de avaliação de impacto, diagnósticos ambientais e recuperação de áreas degradadas, bem como para a criação de um inventário dos recursos naturais local.

\section{- Conservação dos espaços, espécies e elementos singulares}

1. Catalogação das espécies da fauna e flora local: Convênio com as universidades e órgãos de pesquisas para a realização de um inventário das espécies animais e vegetais.

2. Substituição do uso da lenha e carvão vegetal no consumo doméstico: Investimento em fontes de energia alternativas.

3. Garantia do funcionamento dos canais, ravinas e tributários, bem como de uma convivência harmônica entre a população e os recursos naturais: Investimento em sensibilização dos proprietários sobre o papel das APPs; Fiscalização do cumprimento da legislação que disciplina o uso do solo. 
Adequação do comportamento ambiental dos agentes socioeconômicos

1. Redução do desmatamento: Conscientização acerca do papel da vegetação para a conservação do solo e quantidade/qualidade da água; Fiscalização quanto ao cumprimento das leis e decretos que disciplinam a exploração e reposição florestal e o uso do solo; Implementação de políticas de geração de renda, reduzindo a dependência em relação à madeira e lenha; Incentivo à difusão de fontes de energia limpas e mais baratas.

2. Adoção de práticas agropecuárias compatíveis com as características do local: Aproveitamento dos saberes locais sobre clima, propriedades dos solos, cultivos, dentre outros no planejamento de práticas agropecuárias; Conscientização sobre a importância da adoção de técnicas de contenção e manutenção das propriedades físicas e químicas do solo; Investimento em assistência técnica pelos órgãos competentes; Criação de mecanismos de incentivo à valorização e escoamento adequado dos produtos advindos da agropecuária local;

3. Regeneração natural e/ou controlada das Áreas de Proteção Permanentes: Sensibilização sobre a importância das APPs para o manejo da microbacia; Realização de estudos diagnósticos acerca da diversidade de espécies nas áreas a serem regeneradas, podendo ser introduzidas espécies da Caatinga que tenham sido extintas na área, de forma a promover a diversidade vegetal; Fiscalização ao cumprimento da legislação ambiental; Regeneração das coroas de proteção das nascentes, as matas ciliares e o entorno dos reservatórios.

4. Criação/manutenção das áreas de Reserva Legal: Sensibilização sobre o significado da Reserva Legal e sua importância para o equilíbrio ambiental local; Investimento em assistência técnica por parte dos órgãos competentes para delimitação dessas áreas e orientação sobre os trâmites legais; Fiscalização acerca da manutenção dessas áreas.

5. Construção de reservatórios de água: Construção de barragens subterrâneas e superficiais, poços e cisternas nas propriedades que ainda não dispõem.

6. Execução de técnicas de recuperação das propriedades do solo: Investimento em assistência técnica pelos órgãos de extensão rural e Universidades; Realização de análise dos parâmetros físico-químicos dos solos degradados; Utilização de adubação orgânica; Delimitação de áreas de pousio nas propriedades; Utilização de cobertura no solo, por espécies vivas ou incorporação de culturas.

7. Reutilização das águas residuárias e destinação dos efluentes: Realização de palestras sobre a importância da água e do reuso que pode ser dado às águas de consumo doméstico; Viabilização da construção de fossas sépticas nas residências que não dispõem.

8. Realização de coleta seletiva dos resíduos sólidos: Realização de palestras sobre matérias primas, recursos renováveis e não renováveis e possibilidade de reciclagem de resíduos, mediante coleta seletiva; Realização de convênios que possibilitem a criação de infra-estrutura que viabilize a coleta seletiva e destinação dos produtos para o mercado, possibilitando a complementação da renda das famílias.

9. Recuperação das áreas degradadas pela extração da argila Bentonita: Realização de estudo detalhado sobre as áreas de extração mineral e deposição de estéril e rejeitos; Formação de convênios com as Universidades para estudar a melhor forma de aproveitamento do material estéril e rejeitos da mineração; Exigência pelos órgãos ambientais do EIA/RIMA e do Plano de Recuperação de Áreas Degradadas - PRAD como pré-requisitos para Licença de Operação; Exigir das empresas mineradoras o fechamento das cavas e taludes, assim como a adoção das 
técnicas de preparo do solo para a introdução de vegetação nativa. Fiscalização acerca do cumprimento do PRAD.

\section{. Impulso ao crescimento econômico sobre bases sustentáveis}

1. Criação de mecanismos de geração e/ou complementação de renda: Criação de estruturas organizativas, de caráter jurídico, para formular ações e conseguir apoio financeiro através de programas oficiais; Criação de mecanismos para que todas as famílias disponham de renda, se ajustando aos níveis que se estabelecem em escalas mais abrangentes; Elaboração de projetos agropecuários estruturantes e sua canalização para financiamento; Valorização dos produtos advindos da agropecuária local, investindo na verticalização da produção e na busca de novos mercados; Aproveitamento da experiência da população na utilização dos derivados do leite e milho que podem ter potenciais mercados regionais e nacionais; Promoção da integração econômica familiar e comunitária, assim como a geração de postos de trabalho públicos ou privados; Incentivo à incorporação de mecanismos ecologicamente corretos para a produção, buscando aproveitar todas as matérias primas, gerando o mínimo possível de resíduos, que devem ter uma destinação adequada.

\section{. Criação de mecanismos democráticos nas comunidades}

1. Aproveitamento dos recursos humanos locais: Desenvolvimento comunitário: Tem-se 80 famílias; Se cada família tiver em média cinco indivíduos, representa em torno de 400 pessoas, que são uma notável força para impulsionar o diálogo e cobrar a colaboração das autoridades de todas as instâncias; Incentivar a vinculação da população com espaços de decisão de gestão, de assistência técnica e investigação científica; Obter e/ou manter condições de conforto e funcionalidade do ambiente familiar: a organização familiar tem dado continuidade às comunidades e sustentado a atividade agropecuária, mesmo com uma série de adversidades como anos de seca crítica, desvalorização dos preços dos produtos. Dessa forma, as instituições como um todo devem priorizar tais investimentos.

O objetivo fundamental da proposta apresentada é impulsionar o desenvolvimento socioambiental, incentivar a participação da população e a equidade no âmbito da tomada de decisões, geração e distribuição de recursos, partindo do contexto das atividades agropecuárias, predominantes na microbacia.

Este modelo de apresentação de propostas de ordenamento também foi utilizado por Sansón et al. (2005), ao formularem um plano de desenvolvimento agropecuário e florestal para um assentamento no município de São Fernando, Chiapas, México, com características socioeconômicas e relação da população com os recursos naturais semelhante a presente. Assim como neste caso, os autores mexicanos objetivaram elaborar uma proposta de desenvolvimento com princípios sustentáveis, partindo do disciplinamento das atividades agropecuárias e florestais e que permita melhorar a qualidade de vida dos habitantes do local.

A presente proposta também constitui um instrumento de gestão ambiental. Entretanto, seus caracteres normativos, fiscalizadores, preventivos e corretivos devem estar harmonizados com uma proposta política crítica e responsável que vise ao exercício da sustentabilidade, envolvendo todo o espaço para evitar privilégios ou penalidades. Esse compromisso político viria a dirimir algumas questões que constituem entraves a essa proposta de desenvolvimento, a exemplo dos conflitos de competências verificados na execução das leis ambientais, embora esta não seja uma problemática eminentemente nacional.

Andrade et al. (2008) ao realizarem uma análise do marco institucional/legal de ordenamento territorial no Chile, constataram como um dos principais desafios a superação dos conflitos de competências quanto à atuação dos órgãos ambientais, visto que existem diversos textos regula- 
mentares nos quais se encontram estabelecidos múltiplos organismos competentes e com funções e atribuições diversas para a regulação do uso do solo.

No Brasil a situação não é diferente, pois o país conta com um inquestionável aparato legal em matéria ambiental, entretanto também existem os mesmos entraves, visto que a Política Nacional de Ordenamento do Território ainda está em construção, o que faz com que o planejamento e gestão territorial se encontram atribuídos aos organismos setoriais nacionais, estaduais e municipais, gerando conflitos de competência. Além disso, no caso de atribuições estabelecidas de forma genérica, não existe uma coordenação de todo o aparato administrativo para delimitar os alcances da regulação e controle de um ou outro organismo competente.

Tendo em vista estas limitações, reforça-se a necessidade da democratização nas tomadas de decisões para se obterem avanços nas políticas públicas que visam a ações interventoras sobre os territórios. Isso não implica numa substimação do papel do Estado, que deve continuar legislando, normatizando e fiscalizando, assim como exercendo o papel de interventor (através de políticas públicas) e também como disciplinador das ações dos principais atores não estatais (ALMEIDA; PEREIRA, 2009, p. 98).

A democratização de que se está tratando diz respeito à oitiva das reivindicações populares, assim como a contemplação dos saberes instituídos nos locais alvos das propostas, visto que no ordenamento do território o conhecimento da dinâmica ambiental é que irá subsidiar as decisões visando alcançar uma melhoria na qualidade ambiental, conforme procurou-se contemplar na presente análise. Além disso, é necessário reconhecer que em espaços comunitários torna-se necessário analisar o sistema de representações que as pessoas fazem de seu ambiente, pois é com base nas mesmas que agem sobre ele.

A título de exemplo, no que concerne à criação de espaços de decisões democráticas, a Lei 9.433/97 prevê processos participativos, podendo ser considerada como um marco norteador na implementação de mecanismos democráticos, pois tem como um dos instrumentos os comitês de bacias, que constituem um foro deliberativo tripartite, onde são hierarquizadas as ações prioritárias para gestão e recuperação das bacias, onde são dirimidos os conflitos quanto ao uso da água, definindo-se regras para a outorga, condições que visam o planejamento de uso e gestão dos recursos hídricos. Além disso, no modelo de gestão desses comitês tem-se a participação da sociedade de uma forma abrangente, ou seja, em interação com os demais processos de uso/ocupação das terras nas bacias.

$\mathrm{Na}$ França, por exemplo, a adoção das bacias hidrográficas como unidades territoriais para implementação e gerenciamento de ações proporcionou uma redução de cerca de $60 \%$ da carga de poluição dos rios. Todo esse êxito obtido mediante a descentralização das decisões e a transparência dos processos (ALMEIDA; PEREIRA, 2009, p. 101).

Entretanto, no Brasil ainda existem muitos desafios a serem superados para uma melhor funcionalidade dos comitês, se fazendo necessária uma maior conscientização da população quanto a importância da conservação ambiental e dos recursos hídricos, uma maior abrangência na divulgação dos princípios, das ações e até mesmo das reuniões, uma maior compreensão do que significa sociedade civil organizada e do papel que representa nos comitês, assim como incorporar todos os atores que tradicionalmente têm sido desprezados nos processos político-decisórios. Mesmo assim, este já é um exemplo de gestão que pode ser considerado para a implementação de um plano de ordenamento, além de constituir um viés de grandes perspectivas para a definição de estratégias de desenvolvimento sustentável.

\section{CONSIDERAÇÕES FINAIS}

As técnicas de geoprocessamento, associadas ao trabalho de campo, permitiram o conhecimento das características do meio físico, bem como das principais classes de uso da terra na Microbacia, sendo a pecuária a principal atividade econômica desenvolvida no local. 
Todos os valores das vulnerabilidades calculados via sistema de atribuição de pesos às variáveis, foram enquadrados na classe muito alta, a exceção da vulnerabilidade social, cujos valores variaram entre $36,05 \%$ e $40,86 \%$, sendo enquadrados na classe alta. Os atenuantes do grau de vulnerabilidade social estão relacionados aos programas sociais promovidos pelo Governo Federal, que ampliaram o consumo de alimentos e de alguns bens de consumo duráveis. No entanto, os altos valores ainda mostram o grau de pobreza da população do campo, sua insegurança e sua incapacidade de, por si só, fazer mudanças significativas, visando um desenvolvimento sustentável. Eles mostram a fragilidade do sistema.

A integração entre os dados oriundos da interpretação das imagens de satélite e das informações dos questionários de campo possibilitou um conhecimento satisfatório da realidade local, subsidiando as propostas de intervenção apresentadas, a serem implementadas pelo conjunto sociedade organizada, poderes públicos e instituições.

\section{REFERÊNCIA BIBLIOGRÁFICA}

ALENCAR, M. L. S. EI Niño de 1997/1998: sistemas hídricos, degradação ambiental e vulnerabilidades no Cariri Paraibano. 2004. 170 f. Dissertação (Mestrado em Engenharia Agrícola). Universidade Federal de Campina Grande, Campina Grande, 2004.

ALMEIDA, F. G.; PEREIRA, L. F. M. O papel da distribuição e da gestão dos recursos hídricos no ordenamento territorial brasileiro. In: ALMEIDA, F. G.; SOARES, L. A. A. (Org.). Ordenamento territorial: coletânea de textos com diferentes abordagens no contexto brasileiro. Rio de Janeiro: Bertrand Brasil, 2009, 288 p., p.85-113.

ANDRADE, B.; ARENAS, F.; GUIJÓN, R. Revisión crítica del marco institucional y legal chileno de ordenamiento territorial: el caso de la zona costera. Revista de Geografía Norte Grande, v. 41, 2008. p. 23-48.

BALIEIRO, F. C. Caracterização de substratos para fins de recuperação de áreas degradadas. In: TAVARES, S. R. L. Curso de recuperação de áreas degradadas: a visão da Ciência do Solo no contexto do diagnóstico, manejo, indicadores de monitoramento e estratégias de recuperação. Rio de Janeiro: Embrapa Solos, 2008.

BARBOSA, M. P. Vulnerabilidade de risco a desastre. Campina Grande: Departamento de Engenharia Agrícola/UFPB, 1997, 87 p. (apostila).

BRASIL. Constituição da República Federativa do Brasil de 1988. Disponível em: < http://www.planalto. gov.br/ccivil_03/constituicao.htm>. Acesso em: 10 set. 2008.

BRASIL. Lei no 4.504, de 30 de novembro de 1964. Dispõe sobre o Estatuto da Terra e dá outras providências. Disponível em: <http://www.lei.adv.br/4504>. Acesso em: 06 set. 2008.

BRASIL. Lei no 4.771, de 15 de set. de 1965. Institui o Novo Código Florestal. Brasília, 1965. Disponível em: <http://www.planalto.gov.br/ccivil.htm>. Acesso em: 10 set. 2008.

BRASIL. Lei n 6.938, de 31 de agosto de 1981. Dispõe sobre a Política Nacional do Meio Ambiente, seus fins e mecanismos de formulação e aplicação, e dá outras providências. Disponível em: <http://www.lei. adv.br/6938-81.htm>. Acesso em: 04 set. 2008.

BRASIL. Lei $\mathbf{n}^{\circ}$ 8.171, de 17 de janeiro de 1991. Dispõe sobre a política agrícola. Disponível em: <http:// www.lei.adv.br/8171-91.htm>. Acesso em: 12 ago. 2008.

BRASIL. Lei no 9.433, de janeiro de 1997. Institui a Política Nacional de Recursos Hídricos, cria o Sistema Nacional de Recursos Hídricos, Brasília, DF, 1997. Disponível em: < http://www.planalto.gov.br/ccivil_03/ LEIS/19433.htm>. Acesso em: 10 set. 2008.

BRASIL. Resolução CONAMA no 303, de 20 de março de 2002. Dispõe sobre parâmetros, definições e limites de Áreas de Preservação Permanente. Disponível em: <http://www. mma.gov.br/port/conama/res/ res02/res30302.html>. Acesso em: 10 set. 2008.

CÂMARA, G. et al. SPRING: integrating remote sensing and gis by objectoriented data modellling. Computers \& graphics, v. 20, n. 3, mai.jun., 1996. p. 395-403.

DE BIASI, M. A. Carta Clinográfica: os métodos de representação e sua confecção. R. do Departamento de Geografia, São Paulo, n. 6, 1992. p. 45-60. 
EMBRAPA. Empresa Brasileira de Pesquisa Agropecuária. Sistema Brasileiro de Classificação de Solos. $2^{\mathrm{a}}$. ed. Rio de Janeiro: EMBRAPA SOLOS, 2006, 306 p.

GOVERNO DO ESTADO DA PARAÍBA. Agência Executiva de Águas do Estado da Paraíba - AESA. Disponível em: <http: www.aesa.pb.gov.br>. Acesso em: 18 ago. 2008.

GOVERNO DO ESTADO DA PARAÍBA. Companhia de Desenvolvimento de Recursos Minerais da Paraíba - CDRM. Fotografias Aéreas, 1967. Escala 1:70.000.

GOVERNO DO ESTADO DA PARAÍBA. Zoneamento Agropecuário do Estado da Paraíba. Relatório ZAP-B-1041. João Pessoa: Secretaria da Agricultura e Abastecimento/UFPB/FUNAPE, 1978.

GOVERNO DO ESTADO DA PARAÍBA. Decreto 24.414/2003, de 27 de setembro de 2003. Dispõe sobre a exploração florestal no Estado. Disponível em: $<$ http://www.sudema.pb.gov.br.>. Acesso em: 26 jan. 2010. GOVERNO DO ESTADO DA PARAÍBA. Decreto 24.416/2003, de 27 de setembro de 2003. Dispõe sobre a reposição florestal obrigatória no Estado. Disponível em: <http://www.sudema.pb.gov.br.>. Acesso em: 26 jan. 2010.

GOVERNO DO ESTADO DA PARAÍBA. Decreto 24.417/2003, de 27 de setembro de 2003. Dispõe sobre o uso alternativo do solo. Disponível em: <http://www.sudema.pb.gov.br.>. Acesso em: 26 jan. 2010.

GOVERNO DO ESTADO DA PARAÍBA. Lei n. 6002/1994, de 29 de dezembro de 1994. Institui o Código Florestal do Estado da Paraíba e suas diretrizes. Disponível em: <http://www.sudema.pb.gov.br.>. Acesso em: 26 jan. 2010.

GOVERNO DO ESTADO DA PARAÍBA. Lei n. 6.308, de 02 de julho de 1997. Institui a Política Estadual de Recursos Hídricos e suas diretrizes. Disponível em: <http://www.sudema.pb.gov.br>. Acesso em: 26 jan. 2010.

HOGAN, D. J; MARANDOLA JR. E. Vulnerabilidades e perigos naturais nos estudos de população e ambiente. In: HOGAN, D. J. (Org.) Dinâmica populacional e mudança ambiental: cenários para o desenvolvimento brasileiro. Campinas: NEPO/UNICAMP, 2007, p. 73-85.

IBGE. Instituto Brasileiro de Geografia e Estatística. Censo Agropecuário 2006. Disponível em: $<$ http:// www.ibge.gov.br/cidadesat/topwindow.htm?1> Acesso: 18 ago. 2008.

INPE. Instituto Nacional de Pesquisas Espaciais - CBERS, Satélite Sino-brasileiro de Recursos Terrestres. Imagem de Satélite de Campina Grande, 2007. Altura: 6894. Largura: 6398, Formato: Tiff, Res. 20 m. Disponível em: <http://www.inpe.br/>. Acesso em: 06 abr. 2007.

MARANDOLA JR., E; HOGAN, D. J. Vulnerabilidades e Riscos: entre Geografia e Demografia. R. Bras. Est. Populacionais, São Paulo, v. 22, n. 1, 2005. p. 29-53.

MELO, J. A. B. de. Diagnóstico Físico-conservacionista e das vulnerabilidades como subsídio ao ordenamento territorial da Microbacia do Riacho do Tronco, Boa Vista, PB. 2010. 218 f. Tese (Doutorado em Recursos Naturais). Campina Grande: Universidade Federal de Campina Grande, 2010.

OLIVEIRA, P. T. B.; TROVÃO, D. M. B. M.; CARVALHO, E. C. D.; SOUZA, B. C.; FERREIRA, L. M. R. Florística e fitossociologia de quatro remanescentes vegetacionais em áreas de Serra no Cariri paraibano. Revista Caatinga, Mossoró, v. 22, n. 4, out./dez. 2009. p. 169/178.

OREA, D. G. Ordenación Territorial. 2a Ed. Madrid: Ediciones Mundi-Prensa, 2007, 766 p.

PEGADO, C. M. A. et al. M. Efeitos da invasão biológica de algaroba (Prosopis juliflora [Sw] DC.), sobre a composição e a estrutura do estrato arbustivo-arbóreo da Caatinga no Município de Monteiro, PB, Brasil. R. Acta Botânica Brasilica, São Paulo, v. 20, n. 4, out./dez. 2006.

PEREIRA, R. A.; BARBOSA, M. F. N. Diagnóstico socioeconômico e ambiental de uma microbacia hidrográfica no semi-árido paraibano. Engenharia Ambiental, Espírito Santo do Pinhal, v. 6, n. 1, jan./abr. 2009. p. 137-153.

SANSÓN, L. M. et al. Formulación de un plan de desarrollo agropecuario y forestal para uma comunidad ejidal del municipio de San Fernando, Chiapas, México. Revista Mundo Agrario. v. 5, n. 10, 2005. p. 1-28.

SCAPINI, G. P. Diagnóstico Físico-Conservacionista e sua relação com a sedimentação e preferências de paisagem. 2006. 94 fls. Dissertação (Mestrado em Engenharia Florestal). Santa Maria, RS: Universidade Federal de Santa Maria, 2006. 
SOARES, P. C.; FIORI, A. P. Lógica e sistemática na análise e interpretação de fotografias aéreas em Geologia. Revista Notícias Geomorfológicas, v.16, n.32, 1976. p.71-104.

SOUSA, R. F. de. Geoprocessamento no estudo das terras com vista ao desenvolvimento sustentado, com diminuição dos riscos, 2007. 180 f. Tese (Doutorado em Engenharia Agrícola) - Universidade Federal da Paraíba, Campina Grande, 2007.

SRTM. Shuttle Radar Topography Mission. Mapping the world in 3 dimensions. Disponível em: $<$ http:// srtm.usgs.gov/>. Acesso: 24 out. 2008.

SUDENE, Superintendência de Desenvolvimento do Nordeste. Carta Topográfica do Município de Boqueirão, PB (SB-24-Z-D-III), 1972. Escala 1:100.000.

UNEP. United Nations Environment Programme. World Atlas of Desertification. Londres: UNEP/Edward Arnold, 1991, $69 \mathrm{p}$.

VENEZIANI, P.; ANJOS, C. E. dos. Metodologia de interp retação de dados de sensoriamento remoto e aplicações em geologia. São José dos Campos: INPE, 1982.

Trabalho enviado em maio de 2011

Trabalho aceito em julho de 2011 